\title{
Expressão da relação retórica de concessão em elocuções formais e entrevistas orais*
}

\author{
Expression of concession rhetorical relation in formal \\ speeches and oral interviews
}

\section{Juliano Desiderato Antonio Universidade Estadual de Maringá}

Resumo

O objetivo deste trabalho é investigar como a relação retórica de concessão é expressa por meio de oraçōes hipotáticas adverbiais concessivas em um corpus constituído por elocuções formais (aulas) e entrevistas. A perspectiva teórica adotada foi da RST (Rhetorical Structure Theory - Teoria da Estrutura Retórica do Texto), uma teoria que parte do pressuposto de que, além do conteúdo explícito veiculado pelas orações, há relações retóricas que surgem das relações que se estabelecem entre partes do texto. Utilizaram-se parâmetros da Gramática Discursivo-Funcional (GDF) para a caracterização das construções hipotáticas adverbiais concessivas utilizadas pelos falantes para expressar a relação retórica de concessão. Pretendeu-se com isso fornecer pistas para auxiliar na identificação dessa relação.

\section{Palavras-chave}

Estrutura Retórica do Texto, RST, Gramática discursivo-funcional, GDF. Concessão, Orações concessivas. 


\section{Abstract}

The aim of this paper is to investigate the expression of concession rhetorical relation as expressed by means of concessive hypotactic adverbial clauses in formal speeches (university lectures) and oral interviews. The research is theoretically based on RST (Rhetorical Structure Theory), a theory that assumes that besides the explicit content conveyed by clauses, rhetorical relations arise from the combination of parts of texts. Parameters from Functional Discourse Grammar (FDG) were used in order to characterize the hypotactic concessive constructions used by the speakers to express concession rhetorical relation.

\section{Keywords}

RST, Rhetorical Structure Theory, Functional Discourse Grammar, FDG, Concession, Concession clauses. 


\section{Introdução}

lém do conteúdo explícito veiculado pelas orações de um texto, há
proposições implícitas, as chamadas proposiçóes relacionais, que surgem
das relações que se estabelecem entre partes do texto. Para Mann e Thompson (1983), o fenômeno das proposições relacionais é combinacional, definido no âmbito textual, ou seja, as proposições relacionais são resultantes da combinação de partes do texto, sejam orações ou porções maiores de texto. As proposiçôes relacionais recebem outros rótulos como "relações discursivas", "relações de coerência” ou "relaçōes retóricas" (TABOADA, 2009, p. 127).

Um tratamento adequado a essa questão das proposições relacionais é oferecido pela RST (Rhetorical Structure Theory-Teoria da Estrutura Retórica do Texto), uma teoria descritiva que tem por objeto o estudo da organização dos textos, caracterizando as relações que se estabelecem entre as partes do texto (MANN; THOMPSON, 1988; MATTHIESSEN; THOMPSON, 1988; MANN, MATTHIESSEN; THOMPSON, 1992).

Ao tratar das relações retóricas tanto no nível discursivo quanto no nível gramatical (combinação entre orações), a RST demonstra sua filiação à Linguística Funcional, um grupo de teorias que consideram essencial para o estudo da língua a função dos elementos linguísticos na comunicação (BUTLER, 2003; NEVES, 1997; NICHOLS, 1984). Mais especificamente, a RST foi desenvolvida no âmbito de outras duas teorias funcionalistas: a Gramática Sistêmico-Funcional de Halliday e o Funcionalismo da Costa-Oeste dos Estados Unidos (ANTONIO, 2009).

Na visão funcionalista, a comunicação não se dá por meio de frases, mas sim por meio do "discurso multiproposicional, organizado em estruturas que reconhecemos como caracterizando conversações, palestras, encontros de comitês, cartas formais e informais dentre outras" (BUTLER, 2003, p. 28, tradução nossa). Além disso, os chamados componentes 'gramaticais' da língua (regras fonológicas, morfológicas, sintáticas e semânticas) são considerados 
instrumentais em relação às regras de uso das expressões linguísticas (DIK, 1989), uma vez que o correlato psicológico de uma teoria funcionalista é a competência comunicativa do falante (DIK, 1989), termo utilizado por Hymes (1987) para se referir à capacidade que o falante tem não apenas de produzir enunciados gramaticalmente corretos, mas também adequados à situação comunicativa.

Neste artigo, pretende-se investigar como a relação retórica de concessão é expressa por meio de orações hipotáticas adverbiais concessivas em um corpus constituído por elocuçôes formais (aulas) e entrevistas. Embora possa parecer óbvia uma biunivocidade entre relação de concessão e orações adverbiais concessivas, é preciso observar que, na visão da RST, as proposições relacionais surgem no texto independentemente de sinais específicos de sua existência: não há necessidade de inclusão, no texto, de elementos linguísticos que tenham por função indicar as relações estabelecidas (MANN; THOMPSON, 1983). Pesquisas têm sido realizadas no sentido de identificar os meios linguísticos utilizados pelos falantes para marcar as relações retóricas. Alguns meios já descritos são marcadores discursivos, tempo e aspecto verbais, combinação entre oraçōes (paratáticas/ hipotáticas). Outras pesquisas têm demonstrado também que as proposições relacionais podem ser reconhecidas pelo destinatário do texto sem ser necessariamente expressas por alguma marca formal (TABOADA, 2006). Assim, como afirma Taboada (2009), provavelmente não há um mapeamento biunívoco entre uma relação e algum tipo de marcação.

A identificação das relações retóricas pelo analista se baseia em julgamentos funcionais e semânticos, que buscam identificar a função de cada porção de texto, e verificar como o texto produz o efeito desejado em seu possível receptor. Esses julgamentos são de plausibilidade, pois o analista tem acesso ao texto, tem conhecimento do contexto em que o texto foi produzido e das convençōes culturais do produtor do texto e de seus possíveis receptores, mas não tem acesso direto ao produtor do texto ou aos seus possíveis receptores, de forma que não pode afirmar com certeza que esta ou aquela análise é a correta, mas pode sugerir uma análise plausível (MANN; THOMPSON, 1988).

Serão utilizados parâmetros da Gramática Discursivo-Funcional (de agora em diante, GDF) para a caracterização das construçóes hipotáticas adverbiais concessivas utilizadas pelos falantes para expressar a relação retórica de concessão. Pretende-se, dessa forma, fornecer pistas que auxiliem na identificação dessa relação. 


\section{Fundamentação teórica}

\subsection{RST e GDF}

Na visão da RST, as proposições que surgem das relações entre partes do texto permeiam todo o texto, desde as porções maiores até as relaçōes estabelecidas entre duas orações (MATTHIESSEN; THOMPSON, 1988). De acordo com a teoria, são essas relações que dão coerência ao texto, conferindo unidade e permitindo que o produtor atinja seus propósitos com o texto que produziu.

No que diz respeito à organização, as relaçóes podem ser de dois tipos (MANN; THOMPSON, 1988):

a) núcleo-satélite (hipotáticas), nas quais uma porção do texto (satélite - S) é ancilar da outra (núcleo - N), como no diagrama 1 a seguir, em que um arco vai da porção que serve de subsídio para a porção que funciona como núcleo.

b) multinucleares (paratáticas), nas quais uma porção do texto não é ancilar da outra, sendo cada porção um núcleo distinto, como no diagrama 2 a seguir.

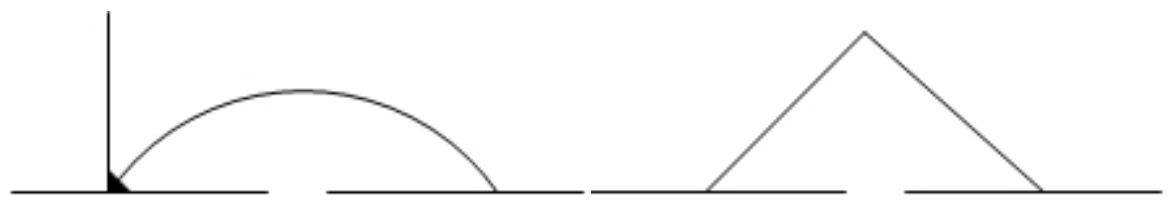

DIAGRAMA 1 - Esquema de relação núcleo-satélite
DIAGRAMA 2 - Esquema de relação multinuclear

Uma lista de aproximadamente vinte e cinco relações foi estabelecida por Mann e Thompson (1988) após a análise de centenas de textos, por meio da RST. Essa lista não representa um rol fechado, mas um grupo de relações suficiente para descrever a maioria dos textos. ${ }^{1}$

As relações retóricas são definidas pela RST com base em quatro características: a) restrições sobre o núcleo; b) restrições sobre o satélite; c) restrições sobre a combinação entre o núcleo e o satélite; d) efeito. De acordo com Gómez-González e Taboada (2005), a RST tem um viés em relação ao criador do texto, de forma que a característica mais importante na definição das relaçóes é o efeito que o produtor do texto deseja atingir em seu destinatário, ou seja, sua intenção. Apresenta-se, no quadro 1 a seguir, a definição da relação de concessão, objeto de investigação deste trabalho: 
QUADRO 1

Definição da relação de concessão

\begin{tabular}{|c|c|c|c|}
\hline $\begin{array}{l}\text { Nome } \\
\text { da } \\
\text { relação }\end{array}$ & $\begin{array}{c}\text { Restriçōes sobre N } \\
\text { ou sobre } S \\
\text { individualmente }\end{array}$ & Restriçóes sobre $\mathrm{N}+\mathrm{S}$ & $\begin{array}{c}\text { Intenção } \\
\text { falante/escritor }\end{array}$ \\
\hline Concessão & $\begin{array}{l}\text { Sobre N: o falante/ } \\
\text { escritor tem conceito } \\
\text { positivo por N. } \\
\text { Sobre S: o falante/ } \\
\text { escritor não está } \\
\text { defendendo que S } \\
\text { não tenha algo a ver. }\end{array}$ & $\begin{array}{l}\text { O falante/escritor reconhece } \\
\text { uma potencial ou aparente } \\
\text { incompatibilidade entre } \mathrm{N} \text { e } \mathrm{S} \text {; } \\
\text { reconhecer a compatibilidade } \\
\text { entre } \mathrm{N} \text { e } \mathrm{S} \text { aumenta o conceito } \\
\text { positivo do ouvinte/leitor em } \\
\text { relação a } \mathrm{N} \text {. }\end{array}$ & $\begin{array}{l}\text { O conceito positivo } \\
\text { do ouvinte/leitor em } \\
\text { relação a } \mathrm{N} \text { aumenta. }\end{array}$ \\
\hline
\end{tabular}

No que diz respeito às funções globais, as relações da RST podem ser divididas em dois grupos (MATTHIESSEN; THOMPSON, 1988):

a) relaçôes que dizem respeito ao assunto (subject matter), que têm como efeito levar o enunciatário a reconhecer a relação em questão: elaboração, circunstância, solução, causa, resultado, propósito, condição, interpretação, meio, avaliação, reafirmação, resumo, sequência, contraste;

b) relações que dizem respeito à apresentação da relação (presentational), que têm como efeito aumentar a inclinação do enunciatário a agir de acordo com o conteúdo do núcleo, concordar com o conteúdo do núcleo, acreditar no conteúdo do núcleo ou aceitar o conteúdo do núcleo: motivação, antítese, fundo, competência, evidência, justificativa, concessão, preparação.

A GDF, por sua vez, é um modelo de estrutura da linguagem tipologicamente baseado, e seus autores propõem que seja um componente gramatical de uma teoria mais ampla da interação verbal (HENGEVELD; MACKENZIE, 2008).

O componente gramatical do modelo apresenta conexões com outros módulos não gramaticais: componente conceitual, componente contextual e componente de saída. Uma das principais características da GDF e uma das principais diferenças em relação ao modelo do qual se originou (Functional Grammar-FG - DIK, 1989) é ter uma organização top-down. Isso quer dizer que a GDF parte das intenções do falante e vai até a articulação das expressões linguísticas. Embora essa organização reflita a organização do processamento da linguagem, Hengeveld e Mackenzie (2008) afirmam que a GDF não se propõe 
a ser um modelo do falante, mas um modelo de gramática que tem evidência psicolinguística.

Outra característica do modelo salientada pelos autores é o fato de tomar o Ato Discursivo como unidade básica de análise, e não mais a oração, como fazia a FG. Um Ato Discursivo pode ser composto por uma interjeição, por uma oração, por fragmentos de orações, por locuções ou por palavras. Quando combinados, os Atos Discursivos formam um Movimento (Move, em inglês), definido por Kroon (1997, p. 20) como "a mínima unidade livre do discurso capaz de participar de uma estrutura de interação". Os Atos Discursivos e os Movimentos fazem parte de um dos quatro níveis do componente gramatical da GDF, o nível interpessoal.

No componente gramatical, os níveis interpessoal e representacional são responsáveis pela formulação, entendida pelos autores como "as regras que determinam o que constitui representaçôes pragmáticas e semânticas subjacentes válidas em uma língua" (HENGEVELD; MACKENZIE, 2008, p. 2), ao passo que os níveis morfossintático e fonológico são responsáveis pela codificação, entendida pelos autores como "as regras que convertem essas representaçôes pragmáticas e semânticas em regras morfossintáticas e fonológicas" (HENGEVELD; MACKENZIE, 2008, p. 2).

Embora sejam teorias funcionalistas de vertentes distintas, é possível observar tanto na RST quanto na GDF um paralelo com as metafunções de Halliday (1970; 1973). Na proposta da RST, as relações que dizem respeito ao assunto, que têm como objetivo levar o destinatário a reconhecer a existência da relação, podem ser associadas à metafunção ideacional, responsável pela construção das experiências do usuário de uma língua natural. Caso o destinatário não reconheça as relações que se estabelecem entre as orações ou entre as partes do texto, não conseguirá calcular sua coerência. Por outro lado, as relações que dizem respeito à apresentação da relação, utilizadas pelo falante com o objetivo de agir sobre o destinatário do texto, levando-o a concordar, acreditar ou agir de acordo com o conteúdo da porção de texto que constitui o núcleo, podem ser associadas à função interpessoal, responsável pelos recursos gramaticais utilizados pelo falante para interagir com seu interlocutor. Caso o destinatário não reconheça a relação, os objetivos do produtor do texto não serão alcançados, uma vez que seu interlocutor não realizará as ações pretendidas pelo falante. Na proposta da GDF, observa-se que os níveis de formulação também são influenciados pela proposta de Halliday. De acordo com Hengeveld e Mackenzie (2008, p. 128), 
"o nível representacional lida com os aspectos semânticos de uma unidade linguística” (tradução nossa), e "o termo 'semântica' está limitado às maneiras pelas quais a língua se relaciona com o mundo extralinguístico que ela descreve" (tradução nossa). O nível interpessoal apresenta as mesmas características do nível interpessoal de Halliday: "esse é o nível que lida com todos os aspectos formais de uma unidade linguística que reflete seu papel na interação entre o falante e o destinatário" (tradução nossa) (HENGEVELD; MACKENZIE, 2008, p. 46).

Procurando estabelecer um diálogo entre a RST e a GDF, GómezGonzález e Taboada (2005) apresentam a possibilidade de acomodar relações de coerência da RST na GDF, classificando as relações em níveis. De acordo com as autoras, o próprio Dik (1997) já havia sugerido essa possibilidade, atribuindo relaçôes discursivo-funcionais ao nível do ato retórico (interpessoal) ou ao nível do assunto (representacional). Assim, relações da RST como motivação, fundo, antítese, concessão e solução ficariam alocadas no nível interpessoal, e relações como elaboração, condição, propósito e circunstância seriam do nível do assunto.

Ainda segundo Gómez-González e Taboada (2005), Kroon (1997) também argumenta a favor de uma classificação bipartida das relações de coerência. A autora defende a existência de relações de interação e de relações retóricas. As do primeiro tipo integrariam o nível interacional do discurso, ao passo que as do segundo tipo fariam parte do nível retórico ou representacional.

Para Gómez-González e Taboada (2005), essa distinção entre função semântica/ função pragmática das relações tem base na proposta de van Dijk (1979) para distinguir os conectivos de acordo com o tipo de relação estabelecida: "os conectivos pragmáticos expressam relações entre atos de fala, ao passo que os conectivos semânticos expressam relações entre fatos denotados" (p. 449).

Dessa forma, de acordo com a proposta de Gómez-González e Taboada (2005), as relações da RST que dizem respeito ao assunto podem ser acomodadas na GDF no nível representacional, e as relações que dizem respeito à apresentação da relação podem ser acomodadas no nível interpessoal.

Outra questão a ser considerada no possível estabelecimento de um diálogo RST-GDF é o fato de a GDF restringir as relações de coerência apenas aos casos em que há uma marca linguística de que há uma relação. Nesse caso, a proposta de Gómez-González e Taboada (2005) é que se investigue além dos conectivos ou marcadores discursivos procurando por essas marcas. As autoras sugerem outras formas de marcação, como tempo, modo, forma finita do verbo, encaixamento sintático, etc. 


\subsection{Orações adverbiais concessivas}

Segundo Neves (2000), as construções concessivas, juntamente com as adversativas, têm o significado básico de "contrariedade à expectativa" (p. 864). A autora distingue três tipos de construções concessivas: factuais/reais, contrafactuais/irreais e eventuais.

Nas construções do primeiro tipo, apesar da realização/da verdade da oração concessiva, segue-se a realização/a verdade da oração principal. O exemplo (1) é apresentado pela autora (p. 866):

(1) Embora fosse um amigo recente e reticente, já lhe tinha emprestado pequenas quantias.

Nas construções do segundo tipo, apesar da não realização/da falsidade da oração concessiva, segue-se a não realização/a falsidade da oração principal. O exemplo (2) é apresentado pela autora (p. 866):

(2) O semblante sereno de uma vaca, aquele ar bovino imperturbável de quem está sempre filosofando, lhe é simplesmente inevitável, pois mesmo que pudesse querer, a vaca não poderia sorrir nem chorar.

Nas construções do terceiro tipo, dada a potencialidade da oração concessiva, não necessariamente se segue a realização/a verdade nem a não realização/a falsidade da oração principal. O exemplo (3) é apresentado pela autora (p. 866):

(3) Mas, ainda que eu salve o ratinho branco, outro terá de correr em seu lugar.

A autora ainda distingue o nível em que ocorre a relação concessiva com base na teoria dos três domínios de Sweetser (1990). Assim, a relação pode ocorrer entre estados de coisas, como no exemplo (4) (p. 872), entre proposições, passando pelo julgamento do falante, como no exemplo (5) (p. 872), e entre atos de fala, como no exemplo (6) (p. 873).

(4) Embora seja nativa do centro da Bahia, encontramos lindas colheres de pau, feitas de sebastião-de-arruda, em Congonhas do Campo, MG.

(5) Eu sou homem muito fraco, doente mesmo, embora não pareça.

(6) Ainda que mal pergunte, o senhor é médico? 
Em seu estudo sobre as orações adverbiais no inglês, Pérez Quintero (2002, p. 75) afirma que as construções concessivas "indicam que a situação descrita na oração principal é contrária ao que se espera em relação ao que é expresso na oração subordinada" (tradução nossa). No estudo de Pérez Quintero, baseado em Hengeveld (1998), as orações concessivas são consideradas factuais pressupostas. A factualidade descreve um estado de coisas como real, um conteúdo proposicional como verdadeiro e um ato de fala como assertivo. A pressuposição, no domínio da factualidade, segundo Hengeveld (1998, p. 353), "leva à factividade, isto é, à pressuposição de que um evento é real ou que um conteúdo proposicional é verdadeiro" (tradução nossa).

Dependendo do tipo de entidade designada pela oração, Pérez Quintero (2002) distingue três tipos de construções concessivas: concessão eventiva, concessão epistêmica e concessão ilocucionária.

No caso da concessão eventiva, as entidades designadas são de segunda ordem (estados de coisas). O exemplo (7) a seguir é apresentado pela autora (p. 76):

(7) Although he stepped on the brake, the car didn't slow down.

Embora ele tenha pisado no freio, a velocidade do carro não diminuiu.

No caso da concessão epistêmica, as entidades tratadas nas orações são de terceira ordem (conteúdos proposicionais). O exemplo (8) a seguir é apresentado pela autora (p. 76):

(8) Caroline could do nothing but agree although she would have liked to stay and continue talking with him.

Caroline não poderia fazer nada a não ser concordar, embora ela pudesse ter gostado de ficar e continuar a conversar com ele.

No caso da concessão ilocucionária, entidades designadas pelas orações são de quarta ordem (atos de fala). O exemplo (9) a seguir é apresentado pela autora (p. 76):

(9) She called herself Billie (although her real name is Grace) after her model, her idol, the late Billie Holliday.

Ela se chamava de Billie (embora seu nome real fosse Grace) por causa de seu modelo, seu ídolo, Billie Holliday. 
Crevels (2000) acrescenta ainda um quarto tipo de concessivas, as textuais. De acordo com a autora, as concessivas textuais não modificam apenas uma oração, mas toda uma unidade textual precedente que pode ser composta por várias sentenças. O exemplo (10) a seguir é apresentado pela autora (p. 317):

(10) I speak and write Serbian, Albanian, Turkish and Dutch, but I cannot express my true feelings in any other language than Romani. Although now that I come to think of it, I have done it many times.

Falo e escrevo em sérvio, albanês, turco e holandês, mas não consigo expressar meus verdadeiros sentimentos em nenhuma outra língua além do romeno. Embora agora que eu estou pensando nisso, fiz isso várias vezes.

Crevels (2000) defende que os níveis (eventivo, epistêmico, ilocucionário, textual) em que ocorrem as construções concessivas são diferenciados por propriedades distintivas formais, por exemplo, o uso de diferentes conjunçōes para cada nível.

Utilizando o modelo teórico-metodológico da GDF, Garcia (2010) confirma as hipóteses de Crevels em investigação a respeito das relações concessivas no português falado no interior de São Paulo. A pesquisadora identificou três tipos de construçôes concessivas ligadas aos níveis e às camadas da GDF. A posição ocupada pela relação adverbial na linearização da sentença e as conjunções introdutoras da relação adverbial, que tendem a se especializar de acordo com os diferentes níveis e camadas, permitem a caracterização desses tipos de construções concessivas.

O primeiro tipo de relação concessiva mencionado por Garcia (2010) é do nível representacional. Trata-se de construções constituídas por conteúdos proposicionais. As orações concessivas desse tipo ocorrem antepostas à oração principal e têm a função discursiva de "prevenir algum tipo de objeção por parte do interlocutor" (p. 166). O exemplo (11) é apresentado pela autora:

(11) eu.. apesar de ver esse lado positivo dessa reserva de cotas... eu a princípio sou contra...

O segundo tipo é do nível interpessoal. São construções constituídas por atos discursivos subsidiários. As orações concessivas desse tipo ocorrem pospostas à oração principal e têm como função discursiva "correção do que foi dito anteriormente" ou "preservação da face" (p. 166-167). O exemplo (12) é apresentado pela autora: 
(12) ele era... alcóolatra e isso aí marcou muito apesar que hoje ele não é mais...

O terceiro tipo também é do nível interpessoal. As construções são constituídas por atos discursivos ou movimentos. As oraçōes desse tipo ocorrem independentes e têm como função discursiva "introduzir informações adicionais ao que estava sendo dito" (p. 168), uma vez que "parecem ser inserçôes parentéticas que o falante julga necessário do ponto de vista informacional" (p. 167). O exemplo (13) é apresentado pela autora (p. 149):

(13) éh:: outra coisa... importante em aula particular é você cair especificamente na dúvida dele... às vezes... ele:: chega um aluno às vezes ele fala - "eu não entendi essa matéria” - mas aí ce vendo ce fazendo com ele ce percebe que às vezes o problema não é da matéria o problema é de outra coisa anterior à matemática às vezes ele chega... ah:: a gente tem aluno hoje apesar que melhorou um pouco mas antigamente tinha menor pior ainda às vezes ele não sabe fazer conta...

Mann e Thompson (1985) propõem que a concessão seja concebida não em termos semânticos, mas em termos textuais, como uma relação discursiva. Nessa visão, uma relação de concessão se estabelece entre duas porções de texto $a$ e $b$ (considerando-se $b$ a parte que faz a concessão) se for plausível que o autor do texto (p. 438):

1. tenha conceito positivo por $a$ e queira que seu destinatário tenha conceito positivo por $a$ também;

2. reconheça uma potencial ou aparente incompatibilidade entre as situações apresentadas em $a$ e $b$;

3. considere as situações apresentadas em $a$ e $b$ como compatíveis;

4. acredite que o fato de o destinatário reconhecer essa incompatibilidade aumentará seu conceito positivo por $a$, de forma que será menos provável que o destinatário descarte $a$ em face de possíveis objeções a $a$.

Para Mann e Thompson (1985), ter conceito positivo está relacionado aos objetivos que o produtor do texto almeja atingir em seu destinatário por meio de seu texto, ou seja, significa criar uma atitude de aprovação, interesse, levar o destinatário a acreditar em algo. Segundo os autores, nesse tipo de abordagem, 
as orações não podem ser consideradas isoladamente, pois não seria possível inferir os objetivos do autor do texto. Ainda segundo Mann e Thompson (1985, p. 441),

Somente em termos de contexto discursivo podemos compreender como a concessão é uma 'concessão' de algo: ela concede a incompatibilidade potencial de duas situações para antecipar uma objeção que poderia interferir na crença do destinatário a respeito do argumento que o autor defende. ${ }^{2}$

Essa visão de concessão apresentada por Mann e Thompson (1985) é a base para a definição da relação de concessão na RST (cf. quadro 1). Também justifica sua inclusão, quanto às funçôes globais das relações, entre as que dizem respeito à apresentação da relação (presentational), uma vez que é considerada um "mecanismo que o produtor do texto pode utilizar" (p. 441) para influenciar o destinatário a crer em algo.

No que diz respeito às semelhanças semânticas com as orações adversativas, como foi visto no início desta seção com base em Neves (2000), para Mann e Thompson (1985), as relações de concessão e de contraste diferem na finalidade para que são utilizadas pelos falantes. Ao contrário da relação de concessão, que é utilizada para influenciar o destinatário, a relação de contraste é neutra, utilizada para que o destinatário "reconheça que as situações apresentadas são consideradas semelhantes em muitos aspectos, diferentes em alguns aspectos e comparáveis com respeito a um ou mais desses aspectos"3 (p. 441), ou seja, considerando-se as funções globais, é uma relação que diz respeito ao assunto (subject matter).

\section{Considerações metodológicas}

\subsection{1 corpus da pesquisa}

O corpus da pesquisa é composto por 10 entrevistas e por 5 elocuções formais (aulas) do banco de dados do Grupo de Pesquisas Funcionalistas do Norte/ Noroeste do Paraná (Funcpar).

Os informantes das entrevistas são professores universitários de Maringá (PR) que nasceram na cidade ou residem nela há mais de 10 anos. Para que esses informantes apresentassem um comportamento linguístico mais espontâneo 
durante a entrevista, solicitou-se previamente a cada um deles um artigo científico de sua autoria. Após a leitura do texto, o pesquisador elaborou perguntas sobre o processo de produção do texto em si e sobre os temas tratados no artigo. Observou-se que esse procedimento possibilitou um maior envolvimento dos informantes com o conteúdo do que estavam falando, diminuindo-se o efeito "intimidatório" que o gravador geralmente causa aos entrevistados.

Os informantes das elocuções formais também são professores (de ensino superior ou de ensino médio). Assim como nas entrevistas, os informantes também nasceram em Maringá ou residem nessa cidade há mais de 10 anos. As gravações foram feitas durante aulas e durante apresentaçôes de trabalho, motivo pelo qual se espera um certo grau de formalidade nos textos no que diz respeito ao uso do português considerado "culto". Outras características que devem ser destacadas nesses textos são os papéis e a posse do turno fixados previamente (KOCH \& SOUZA e SILVA, 1996). Por isso, há poucas marcas de interação, o professor ou apresentador de trabalho em geral responde a perguntas feitas pelos alunos ou pela audiência. Esses textos também têm um início bem marcado com a apresentação dos objetivos da aula ou do trabalho, bem como um encerramento no qual os objetivos da aula seguinte são antecipados, como pode ser observado nos exemplos (14) e (15) a seguir:

(14) bom na AUla passada né:: nós fizemos o experimento determinação do nível operante e treino ao bebedouro .. certo?

e:: aí vo::cês éh:: ... vocês registraram naquela folha de registro os/ o que:: vocês obserVAram ... né,

... então os dados foram coleTAdos ... a respeito do experimento que foi realizado né,

... entÃO HOje nós vamos/ eu vou estar passando para vocês ... éh:: o relatório que vai ter que ser FEIto,

... é o trabalho que vocês vão ter que fazer agora com os dados que foram coletados .. tá?

(15) .. e pra isso .. é .. PRImordial nós estudarmos o comportame::nto bioló::gico .. da suspensão.

.. a re::ologia da suspensão.

... o que é isso? 
.. nós vamos deixar pro próximo capítulo,

.. pra próxima aula tá?

.... ah:: gente eu tava esquecendo,

.. óh:: .. presta atenção só um pouquinho.

... as suspensóes .. eu mandei pra vocês por e-mail .. os slides.

.. aqui tem .. o roteiro da aula o programa da aula,

.. e tem xerox,

.. são quatro cinco .. capítulos .. de livros modernos sobre suspensões.

Além disso, podem ser encontrados marcadores "metapedagógicos" como certo? e de referência ao saber já internalizado pelos alunos ou pela audiência, como pode ser observado nos exemplos (16) e (17) a seguir:

(16) .. observe que isso aqui é o PRODUTO,

.. então tem que usar a fórmula da derivada do produto,

.. então presta atenção como eu vou fazer,

.. eu vou deriva PRIME::IRO o cosseno.

... certo?

(17) .. então .. se:: não simplificar,

.. já sabe né,

.. errar em conta .. né::?

\subsection{Parâmetros de análise}

Como se afirmou anteriormente neste trabalho, é necessário que outras marcas formais além do conectivo ou marcador discursivo sejam levadas em conta quando se analisa como são estabelecidas as relações retóricas. Dessa forma, os parâmetros investigados neste trabalho são apresentados a seguir.

\subsubsection{Conectivo}

Pretende-se verificar quais conectivos ou marcadores discursivos são utilizados pelos falantes nas construções concessivas. 


\subsubsection{Camada}

Serão utilizadas as camadas movimento e ato discursivo, pertencentes ao nível interpessoal da GDF, e a camada conteúdo proposicional do nível representacional da GDF.

\subsubsection{Correlação modo-temporal}

Como sugerem Gómez-González e Taboada (2005), o tempo e o modo do verbo foram analisados como forma de caracterizar a expressão da relação de concessão.

\subsubsection{Posição}

Verificou-se também se o fato de a oração adverbial estar anteposta ou posposta à oração principal influencia o tipo de relação estabelecida.

\section{Análise dos dados}

Foram encontradas vinte ocorrências da relação de concessão no corpus. $\mathrm{Na}$ tabela 1, apresenta-se o cruzamento da frequência de ocorrência das camadas das orações que estabelecem relação de concessão com a posição da oração concessiva (anterior ou posposta à oração principal).

\section{TABELA 1}

Tipo de camada e posição da oração concessiva

\begin{tabular}{c|cc|c|c|c|c}
\hline & \multicolumn{2}{|c|}{ Movimento } & \multicolumn{2}{c|}{ Ato discursivo } & \multicolumn{2}{|c}{ Conteúdo proposicional } \\
\cline { 2 - 7 } & $\mathrm{N}$ & $\%$ & $\mathrm{~N}$ & $\%$ & $\mathrm{~N}$ & $\%$ \\
\hline Anterior & 1 & 100 & 2 & 22 & 9 & 90 \\
Posterior & - & - & 7 & 78 & 1 & 10 \\
\hline Total & 1 & 100 & 9 & 100 & 10 & 100 \\
\hline
\end{tabular}

Como pode ser observado, há apenas uma ocorrência da relação de concessão estabelecida entre orações na camada do movimento. Trata-se da ocorrência apresentada no diagrama 3. 


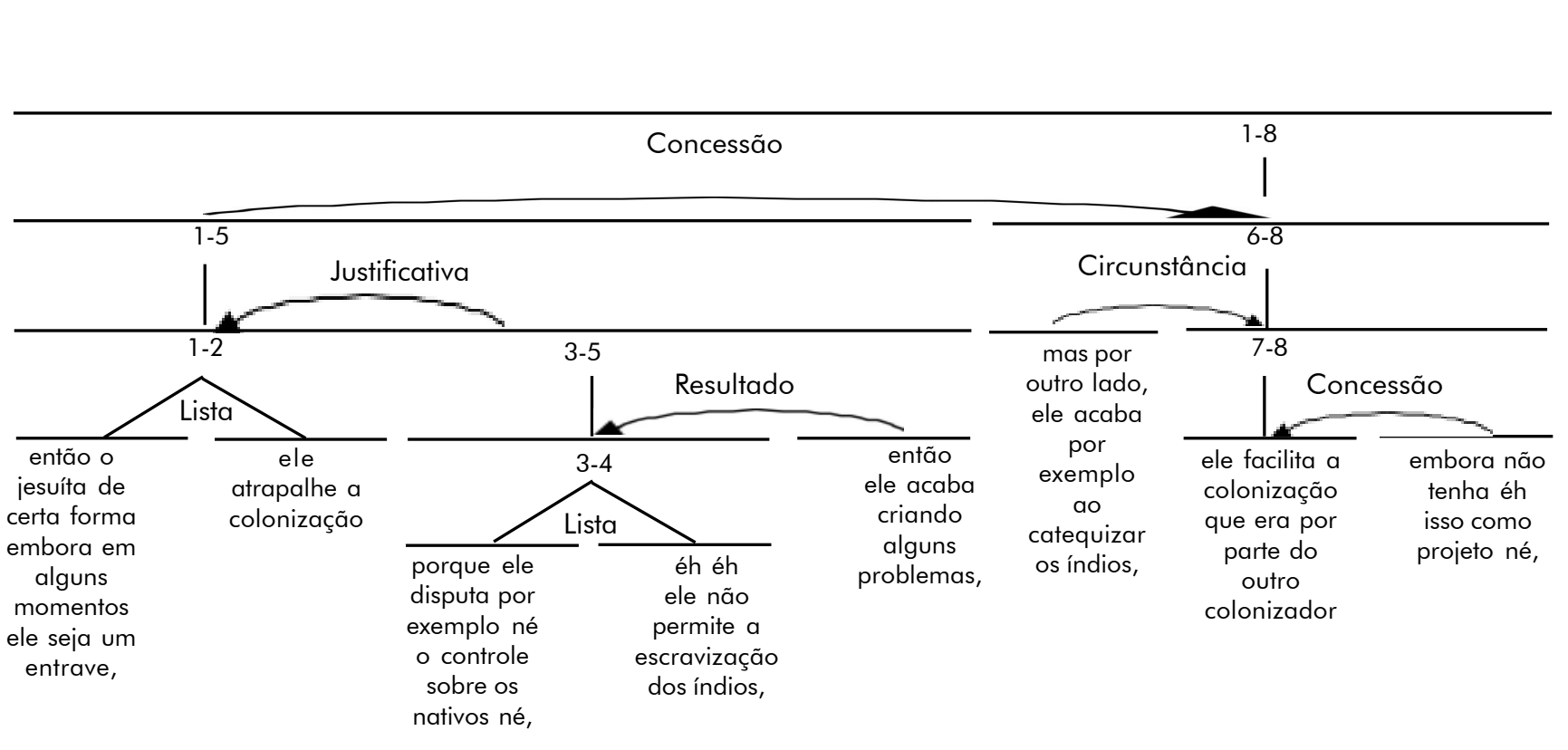

DIAGRAMA 3 - Relação de concessão (movimento) 
Observa-se que a porção textual composta pelas orações concessivas "embora em alguns momentos ele seja um entrave, ele atrapalhe a colonização" ocorre de forma independente. Após as porçôes 1 e 2, o falante justifica sua afirmação nas unidades de 3 a 5 e, quando retoma o fluxo da informação na unidade 6, utiliza a expressão "mas por outro lado" para garantir que seu destinatário reconheça o significado de contrariedade à expectiva, uma vez que o conectivo “embora” já está longe, na unidade 1. Como afirma Garcia (2010, p. 167),

Essas concessivas, denominadas 'desgarradas' por Decat (1999), parecem ser inserções parentéticas que o falante julga necessário do ponto de vista informacional. Após esse 'parêntese', notamos que há uma retomada do fio discursivo geralmente por meio do mas ou do então, que servem para restabelecer o fio discursivo interrompido por causa da inserção da concessão.

A realização de um teste pode ajudar a confirmar que essa construção está na camada do movimento. É possível incluir o modificador "Para encurtar a história" (HENGEVELD; MACKENZIE, 2008, p. 58) antes das unidades 1 e 2: "Para encurtar a história, então o jesuíta de certa forma embora em alguns momentos ele seja um entrave, ele atrapalhe a colonização ...”. Na perspectiva de Crevels (2000), essa construção seria considerada uma concessiva textual.

Assim como na pesquisa de Garcia (2010), as orações concessivas da camada dos atos discursivos ocorrem preferencialmente pospostas à oração principal (78\%), como no exemplo do diagrama 4.

\section{$1-2$}

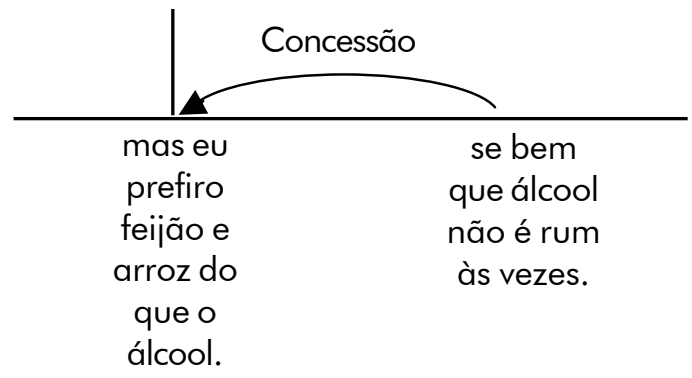

DIAGRAMA 4 - Relação de concessão (atos discursivos) 
Na perspectiva de Crevels (2000), esse tipo de construção corresponde às concessivas ilocucionárias, estabelecidas por elementos de quarta ordem (atos de fala). Observa-se que a oração concessiva posposta exerce função discursiva de adendo ou afterthought (DECAT, 2001), o que pode ser comprovado prosodicamente, uma vez que o ponto final após a unidade 1 indica uma entonação descendente, típica de final de frase. O falante afirma que prefere "arroz e feijão do que álcool", no sentido de combustível. Na oração concessiva, o falante faz uma ressalva, mas o vocábulo álcool, nessa oração, tem sentido de bebida alcóolica, e não de combustível, como na unidade anterior.

As orações concessivas da camada do conteúdo proposicional ocorrem preferencialmente antepostas à oração principal ( $90 \%)$, assim como na pesquisa de Garcia (2010). Na perspectiva de Crevels (2000), trata-se de uma concessiva epistêmica (de terceira ordem), uma vez que os conteúdos veiculados pelas orações sempre passam pela avaliação do falante, como pode ser observado no diagrama 5, em que a oração concessiva está encaixada no predicado evidencial "a gente sabe que".

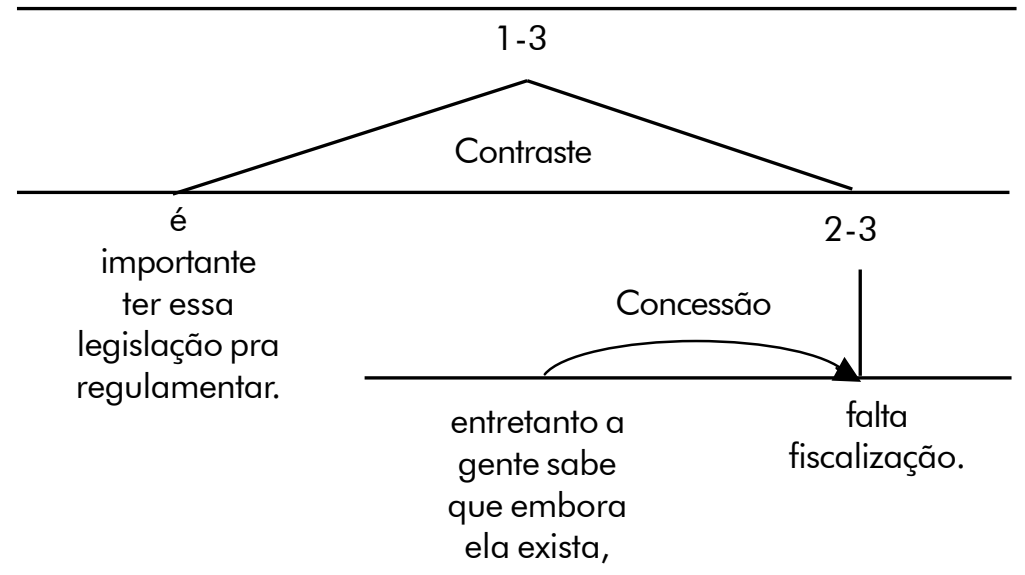

DIAGRAMA 5 - Relação de concessão (conteúdo proposicional)

Segundo Garcia (2010), as construções concessivas desse tipo ocorrem antepostas à oração principal porque têm a função discursiva de "prevenir algum tipo de objeção por parte do interlocutor" (p. 166).

As construções concessivas que ocorrem na camada do movimento e as que ocorrem na camada dos atos discursivos pertencem ao nível interpessoal 
(pragmático) da GDF, ao passo que as construções que ocorrem na camada do conteúdo proposicional pertencem ao nível representacional (semântico). No item 2.1, quando se discutiu a função global das relações retóricas, verificou-se que, de acordo com a RST, a relação de concessão seria do tipo apresentação, que tem viés pragmático, interpessoal. A análise das ocorrências do corpus desta pesquisa demonstra, no entanto, que essa relação pode estar situada também entre as relações que dizem respeito ao assunto, que têm viés semântico, representacional.

No que diz respeito aos conectivos utilizados pelos informantes do corpus, observa-se, na tabela 2, que o embora é o que apresenta frequência de ocorrência mais alta (45\%), provavelmente devido à formalidade do corpus investigado. Locuções conjuntivas com apesar (apesar de/ apesar que) têm frequência de ocorrência um pouco mais baixa (35\%). Mesmo e a locução mesmo que são utilizados pelos informantes do corpus para marcar a relação de concessão em $15 \%$ das ocorrências, e a expressão "se bem que" apresenta uma ocorrência.

TABELA 2

Conectivos

\begin{tabular}{l|c|c}
\hline Conectivo & $\mathrm{N}$ & $\%$ \\
\hline Embora & 9 & 45 \\
Apesar de/ Apesar que & 7 & 35 \\
Mesmo/ Mesmo que & 3 & 15 \\
Se bem que & 1 & 5 \\
\hline Total & 20 & 100 \\
\hline
\end{tabular}

Na tabela 3, apresenta-se a correlação modo-temporal selecionada para cada um desses conectivos. 
TABELA 3

Correlação modo-temporal (relação de concessão)

\begin{tabular}{l|l|c|c}
\hline Conectivo & Oração concessiva-oração nuclear & N & $\%$ \\
\hline \multirow{2}{*}{ Embora } & Pret. Perf. Ind.-Pres. Ind. & 2 & 10 \\
& Pres. Subj.-Pres. Ind. & 6 & 30 \\
& Pres. Subj.-Pret. Perf. Ind. & 1 & 5 \\
\hline \multirow{2}{*}{ Apesar de } & Pret. Perf. Ind.-Pres. Ind. & 1 & 5 \\
& Pres. Subj.-Pres. Ind. & 1 & 5 \\
& Infinitivo-Pres. Ind. & 3 & 15 \\
\hline \multirow{2}{*}{ Apesar que } & Pres. Ind.-Pres. Ind. & 2 & 10 \\
\hline \multirow{2}{*}{ Mesmo } & Pret. Perf. Ind.-Pres. Ind. & 1 & 5 \\
& Gerúndio-Pret. Perf. Ind. & 1 & 5 \\
\hline \multirow{2}{*}{ Mesmo que } & Pres. Subj.-Pres. Ind. & 1 & 5 \\
\hline Se bem que & Pres. Ind.-Pres. Ind. & 1 & 5 \\
\hline \multirow{2}{*}{ Total } & & 20 & 100 \\
\hline
\end{tabular}

Como pode ser observado, a maior frequência de ocorrência é de construções iniciadas por "embora" com o presente do subjuntivo na oração concessiva e presente do indicativo na oração nuclear, como no exemplo (18).

(18) .. e embora eu tenha essas assinatu::ras tudo na mã/ tudo em mãos,

.. não dá pra passar pelo comitê depois de ter feito a pesquisa.

\section{Considerações finais}

Neste trabalho, procurou-se investigar como a relação retórica de concessão é expressa por meio de oraçôes hipotáticas adverbiais concessivas em um corpus constituído por elocuçōes formais (aulas) e entrevistas.

A perspectiva teórica adotada foi da RST (Rhetorical Structure TheoryTeoria da Estrutura Retórica do Texto), uma teoria descritiva que tem por objeto o estudo da organização dos textos, caracterizando as relações que se estabelecem entre as partes do texto. Utilizaram-se parâmetros da Gramática DiscursivoFuncional (GDF) para a caracterização das construções hipotáticas adverbiais concessivas utilizadas pelos falantes para expressar a relação retórica de concessão. Pretendeu-se com isso fornecer pistas para auxiliar na identificação dessa relação. 
No corpus investigado, foram encontradas ocorrências da relação de concessão nas camadas do movimento, dos atos discursivos e do conteúdo proposicional. A ocorrência da camada do movimento tem como função discursiva introduzir informaçōes adicionais ao que estava sendo dito. As ocorrências da camada dos atos discursivos exercem função discursiva de adendo ou afterthought e, por esse motivo, são pospostas à oração principal. As ocorrências da camada do conteúdo proposicional têm a função discursiva de prevenir algum tipo de objeção por parte do interlocutor e, por isso, são antepostas à oração principal. No que diz respeito aos conectivos e à correlação modo-temporal, observou-se que a maior frequência de ocorrência é de construçôes iniciadas por "embora" com o presente do subjuntivo na oração concessiva e presente do indicativo na oração nuclear.

\section{Notas}

* Os resultados apresentados neste artigo são parte do projeto de pós-doutorado intitulado "Uma investigação funcionalista da hipotaxe adverbial e das relaçôes retóricas que organizam o texto", com apoio financeiro da Fundação Araucária (Convênio 093/2010 - UEM - FUNDAÇÃO ARAUCÁRIA), desenvolvido na Unesp/ São José do Rio Preto, sob supervisão da Profa. Dra. Erotilde Goreti Pezatti.

${ }^{1}$ Uma lista com as relações e suas definições pode ser encontrada no site http://www.sfu.ca/rst/07portuguese/definitions.html.

${ }^{2}$ Tradução nossa.

${ }^{3}$ Tradução nossa.

\section{Referências}

ANTONIO, J.D. O texto como objeto de estudo na Linguística Funcional. In: ; NAVARRO, P. O texto como objeto de ensino, de descrição lingüística e de análise textual e discursiva. Maringá: Eduem, 2009. p. 61-80.

BUTLER, C.S. Structure and function: a guide to three major structural-functional theories. Part 1: approaches to the simple clause. Amsterdam/Philadelphia: J. Benjamins, 2003.

CREVELS, M. Concessives on different semantic levels: a typological perspective. In: COUPER-KHULEN, Elizabeth; KORTMANN, Bernd (Ed.). Cause - Condition - Concession - Contrast: Cognitive and Discourse Perspectives. Berlin: Mouton de Gruyter, 2000. p. 313-339. 
DECAT, M.B.N. Por uma abordagem da (in)dependência de cláusulas à luz da noção de "unidade informacional". Scripta, v. 2, n. 4, p. 23-38, 1999.

DECAT, M.B.N. A articulação hipotática adverbial no português em uso. In: et al. (Org.). Aspectos da gramática do português: uma abordagem funcionalista.

Campinas: Mercado de Letras, 2001. p. 103-166.

DIK, C. S. The Theory of Functional Grammar. Dordrecht: Foris, 1989.

DIK, C. S. The theory of Functional Grammar. Part II: Complex and derived constructions. Berlin/ New York: Mouton de Gruyter, 1997.

GARCIA, T.S. As relaçôes concessivas no português falado sob a perspectiva da Gramática Discursivo-Funcional. São José do Rio Preto, 2010. Tese (Doutorado em Estudos Linguísticos). Instituto de Biociências, Letras e Ciências Exatas da Universidade Estadual Paulista Júlio Mesquita Filho, 2010.

GÓMEZ-GONZÁLEZ, M. A.; TABOADA, M. Coherence Relations in Functional Discourse Grammar. In: MACKENZIE, J. L.; GÓMEZ-GONZÁLEZ, M. A. (Ed.). Studies in Functional Discourse Grammar. Berne: Peter Lang, 2005. p. 227-259.

HALLIDAY, M.A.K. Language Structure and Language Function. In: LYONS, J. (Ed.). New Horizons in Linguistics. Harmondsworth: Penguin, 1970.

HALLIDAY, M.A.K. Explorations in the functions of language. Londres: Edward Arnold, 1973.

HENGEVELD, K. Adverbial clauses in the languages of Europe. In: VAN DER AUWERA, J. (Ed.). Adverbial constructions in the languages of Europe. Berlin: Mouton de Gruyter, 1998. p. 335-419.

HENGEVELD, K.; MACKENZIE, J. L. Functional Discourse Grammar. A typologicallybased theory of language structure. Oxford: Oxford University Press, 2008.

HYMES, D. On Communicative Competence. Sociolinguistics, v. 1, p. 219-229, 1987.

KOCH, I. G. V.; SOUZA E SILVA, M. C. P. Atividades de composição do texto falado: a elocução formal. In: CASTILHO, A.T.; BASÍLIO, M. (Org.). Gramática do Português Falado. v. IV: Estudos Descritivos. Campinas/ S. Paulo: Ed. da Unicamp/ Fapesp, 1996. p. 379-410.

KROON, C. Discourse Markers, Discourse Structure and Functional Grammar. In: BUTLER, C. S.; CONNOLLY, J. H.; GATWARD, R. A.; VISMANS, R. M. (Ed.). Discourse and Pragmatics in Functional Grammar. Berlin/New York: Mouton de Gruyter, 1997. p. 17-32. 
MANN, W. C.; THOMPSON, S. A. Relational propositions in Discourse. ISI/RR-, p. 83-115, 1983.

MANN, W. C.; THOMPSON, S. A. A Discourse View of Concession in Written English. In: DELANCEY, S.; TOMLIN, R. (Ed.). Proceedings of the Second Annual Pacific Linguistics Conference, p. 435-447, 1985.

MANN, W. C.; THOMPSON, S. A. Rhetorical Structure Theory: toward a functional theory of text organization. Text, v. 8, n. 3, p. 243-281, 1988.

MANN, W. C.; MATTHIESSEN, C. M. I. M.; THOMPSON, S. A. Rhetorical Structure Theory and text analysis. In: MANN, W. C.; THOMPSON, S. A. (Ed.). Discourse description: diverse linguistic analyses of a fund-raising text. Amsterdam/ Philadelphia: J. Benjamins, 1992. p. 39-77.

MATTHIESSEN, C.; THOMPSON, S. The structure of discourse and 'subordination'. In: HAIMAN, J.; THOMPSON, S. (Ed.). Clause Combining in Grammar and Discourse. Amsterdam/Philadelphia: J. Benjamins, 1988. p. 275-329.

NEVES, M.H.M. A Gramática Funcional. S. Paulo: Martins Fontes, 1997.

NEVES, M.H.M. Gramática de usos do português. S. Paulo: Editora Unesp, 2000.

NICHOLS, J. Functional theories of grammar. Annual review of Anthropology, v. 43, p. 97-117, 1984.

SWEETSER, Eve E. From etymology to pragmatics. Cambridge: Cambridge University Press, 1990.

PÉREZ QUINTERO, M. J. Adverbial subordination in English: a functionalist approach. Amsterdam: Rodopi, 2002.

TABOADA, M. Discourse Markers as Signals (or Not) of Rhetorical Relations. Journal of Pragmatics, v. 38, n. 4, p. 567-592, 2006.

TABOADA, M. Implicit and explicit coherence relations. In: RENKEMA, J. (Ed.). Discourse, of course. Amsterdam: John Benjamins, 2009. p. 127-140.

VAN DIJK, T. A. Pragmatic Connectives. Journal of Pragmatics, v. 3, p. 447-456, 1979. 